\title{
Prevalence of Type 2 Diabetes and Cardiometabolic Risk Parameters in Evros
}

\author{
Sarantoula Ventouri ${ }^{1,2}$, Nikolaos Papanas², Stylianos Tigas' ${ }^{1}$, Christos Nalmpantis ${ }^{3}$, \\ Efstratios Maltezos ${ }^{2}$, Agathocles Tsatsoulis ${ }^{1}$
}

'Department of Endocrinology, School of Health Sciences, University of loannina, loannina, Greece

${ }^{2}$ Diabetes Centre-Diabetic Foot Clinic, Second Department of Internal Medicine, Democritus University of Thrace, University Hospital of Alexandroupolis, Alexandroupolis, Greece

${ }^{3}$ Primary Health Care, Regional Clinics - Health Centers of the Municipality of Traianoupolis, Alexandroupolis, Greece

\begin{abstract}
Introduction: The aim of this study was to estimate the prevalence of Type 2 Diabetes and related metabolic disorders in the Evros region.

Material-Methods: A random sample of 541 people was studied using the Finnish Type 2 Diabetes Risk Score, and measurement of weight, height, waist and hip circumference, blood pressure, as well as Fasting Glucose and Postprandial Glucose with a reflectometer. The participants with a score of $15-20$, score $\geq 20, F G \geq 100 \mathrm{mg} /$ $\mathrm{dl}$ and / or PG $140 \mathrm{mg} / \mathrm{dl}(\mathrm{n}=206)$ were subjected to a oral glucose tolerance test, according to WHO. Lipid profile, metabolic syndrome and cardiovascular risk were also assessed.

Results: Prevalence of DM T2 in the study population was: $29.6 \%$, and that of prediabetes was $10.9 \%$. Obese (Body Mass Index $\geq 30 \mathrm{~kg} / \mathrm{m} 2$ ) were: $52.5 \%$, overweight (BMI $25-30 \mathrm{~kg} / \mathrm{m} 2$ ) were $33.2 \%$ and normal $/$ low weight $(\mathrm{BMl}<25 \mathrm{~kg} / \mathrm{m} 2)$ were $14.1 \%$ of the population. Central obesity with a waist circumference of $\geq 102 \mathrm{~cm}$ had $58,6 \%$ of men and $\geq 88 \mathrm{~cm} 86,8 \%$ of women. Hypertension was $66.9 \%$ of the sample and $58.8 \%$ were on antihypertensive treatment. In 206 subjects, CHOL $200-239 \mathrm{mg} / \mathrm{dl}$ had $32.5 \%$ and $\mathrm{CHOL} \geq 240 \mathrm{mg} / \mathrm{dl} 13.6 \%$. $10.2 \%$ of women had HDL $-\mathrm{CHOL}<45$ and $<35: 3,4 \%$ of men. $5,9 \%$ of subjects had LDL $-\mathrm{CHOL} \geq 160 \mathrm{mg} / \mathrm{dl}$. 18\% of subjects had TG: $200-499 \mathrm{mg} / \mathrm{dl}$ and TG $\geq 500 \mathrm{mg} / \mathrm{dl}: 1.5 \%$. High index Apo-B / Apo-A1 had 19.4\% and $\mathrm{LP}$ (a) $33 \%$ of individuals. $92.2 \%$ of these people had metabolic syndrome.

Conclusions: The upward trend of DM T2 and cardiometabolic risk parameters raises the need for targeted prevention and treatment policies.
\end{abstract}

KEY WORDS: Prevalence, DM Type 2, metabolic disorders, cardiometabolic risk

\section{INTRODUCTION}

The increase in the prevalence of Type 2 Diabetes (DM T2) and related metabolic disorders is a major public health

\section{Corresponding author:}

Sarantoula Ventouri, RN, MSc, MEd, PhDc

2 Thrakis Street, Alexandroupolis, Greece.

Tel. + Fax: +30 2551029723

Tel.: +306937 199641

E-mail: tventouri@gmail.com problem. Although epidemiological studies in Greece differ with regard to methodology self- reporting of known DM T2 or data recording from medical notes vs blood glucose measurements and Oral Glucose Tolerance Test (OGTT), there is an increase in the prevalence of DM T2 in the Greek population as well as globally, with a parallel increase in the prevalence of obesity and the Metabolic Syndrome (MetS), due to the current lifestyle ${ }^{1-4}$.

Submission: 25.08.2021, Acceptance: 31.10.2021 
The aim of the present study was to estimate the prevalence of DM 2 and cardiometabolic risk parameters in the rural population of Evros, using combined methodology. The reason for choosing the area of Evros was because there were available data from previous studies in the region ${ }^{5}$.

\section{MATERIAL - METHODS}

Population study: A random sample of 541 people, 239 men and 302 women, aged $\geq 18$ years, mean age 64, 1 $\pm 8,0$ years) from the villages (Loutra, Antheia, Areistino, Doriko and Nipsa) of the Evros area was studied, in the year 2015-2016.

Methodology: The participants completed a questionnaire (Finnish Type 2 Diabetes Risk Score, FINDRISK) with questions related to the diagnosis of DM T2 and disease expression factors giving the participants points and overall score ${ }^{6}$.Weight, height, waist-hip circumference, blood pressure, Fasting Glucose (FG) and Postprandial Glucose (PG) with reflectometer were recorded. The self-report of the disease with DMT2 was considered known DMT2. These individuals were not subjected to laboratory examination.The individuals, according to the total score, were classified into 5 DMT2 risk levels (Low: score <7, Fairly low: score 7 - 11, Medium: score 12 - 14, High: score 15-20, Very high level: score $\geq 20$ ).

Study criteria: The individuals with a score of 15-20 and score $\geq 20$ and in individuals with $F G \geq 100-125 \mathrm{mg} / \mathrm{dl}$ and / or PG > $140 \mathrm{mg} / \mathrm{dl}$ underwent further investigation with an OGTT after overnight fasting between 8.0-9.0 a.m. according to $\mathrm{WHO}$ criteria ${ }^{7}$, for the diagnosis of unknown DM T2 and Prediabetes (Impaired Glucose Tolerance - IGT and Impaired Fasting Glucose - IFG).

Of the total sample, 139 people $(25.7 \%)$ stated that they had DM T2. Of the remaining 402, 214 met the study criteria, of which 206 people (90 men and 116 women) came for laboratory testing (OGTT). Also, in these individuals a test was performed for the lipid profile (Cholesterol - CHOL, HDL-CHOL, LDL - CHOL and Triglycerides, TG), measurement of apolipoproteins Apo-B and Apo-A1 and $\mathrm{Lp}$ (a).The prevalence of MetS and cardiovascular risk were also calculated based on the atherosclerotic index Apo-B / $A p o-A 1$ and $\operatorname{Lp}(a)^{8-9}$. The laboratory test was performed using their social security number at the University General Hospital of Alexandroupolis.

Bioethics: The study protocol was approved by the University of loannina as part of the thesis of S. Ventouri, under the supervision of Prof. A. Tsatsoulis, and all the participants in the study gave their written consent.

Statistical analysis: The analysis of the data was performed with Superior Performance Software System (SPSS) version 21, using descriptive statistics.

\section{RESULTS}

Demographic Data: The demographic data of the population study, as well as of the selective sample of the study are shown in Table 1 and Table 2.

Prevalence of DM: The prevalence of DM T2 in the study population ( $n=541$ ) was $29.6 \%$ (known DM T2: 25.7\% + unknown DM T2: 3.9\%) and that of Prediabetes was $10.9 \%$ (Table1).The prevalence of DM T2 was $13.3 \%$ in men and $16.3 \%$ among women.

Cardiometabolic risk parameters: The analysis of the cardio-metabolic risk parameters (Table 1) showed;

a) Obesity: $52.5 \%$ of people were obese with Body Mass Index $(\mathrm{BMI}) \geq 30 \mathrm{~kg} / \mathrm{m} 2,33.2 \%$ were overweight

TABLE 1. Demographic data and prevalence of DM 2 and cardiometabolic parameters in the study population

\begin{tabular}{|c|c|c|}
\hline Sex & Number & $\%$ \\
\hline Male & 239 & 44,2 \\
\hline Female & 302 & 55,8 \\
\hline Total & 541 & 100 \\
\hline Age & 541 & $64,1 \pm 8,0$ years \\
\hline Type 2 Diabetes & 160 & 29,6 \\
\hline Known DMT2 & 139 & 25,7 \\
\hline $\begin{array}{l}\text { Unknown DM T2 } \\
\text { Prediabetes } \\
\text { IGT +IFG }\end{array}$ & $\begin{array}{c}21 \\
59 \\
(31+28)\end{array}$ & $\begin{array}{c}3,9 \\
10,9\end{array}$ \\
\hline $\begin{array}{l}\text { Obesity } \\
\mathrm{BMI} \geq 30 \mathrm{~kg} / \mathrm{m}^{2}\end{array}$ & $\begin{array}{c}\mathbf{2 8 4} \\
(130+154)\end{array}$ & $\begin{array}{c}\mathbf{5 2 , 5} \\
M: 54,4 \mathrm{~F}: 51\end{array}$ \\
\hline $\begin{array}{l}\text { Overweight } \\
\text { BMI } 25-30 \mathrm{~kg} / \mathrm{m}^{2}\end{array}$ & $\begin{array}{c}180 \\
(78+102)\end{array}$ & $\begin{array}{c}33,3 \\
M: 32,6 \mathrm{~F}: 33,8\end{array}$ \\
\hline $\begin{array}{l}\text { Normal / underweight } \\
\mathrm{BMI}<25 \mathrm{~kg} / \mathrm{m}^{2}\end{array}$ & $\begin{array}{c}77 \\
(31+46)\end{array}$ & $\begin{array}{c}14,2 \\
M: 13 F: 15,2\end{array}$ \\
\hline \multicolumn{3}{|l|}{ Waist circumference } \\
\hline Male $\geq 102 \mathrm{~cm}$ & 140 & 58,6 \\
\hline Female $\geq 88 \mathrm{~cm}$ & 262 & 86,8 \\
\hline \multicolumn{3}{|l|}{ Waist -to- Hip Ratio } \\
\hline Male WHR $\geq 1,0$ & 121 & 50,6 \\
\hline Female WHR $\geq 0,90$ & 220 & 72,8 \\
\hline $\begin{array}{l}\text { Hypertension } \\
S B P \geq 140 \mathrm{~mm} \mathrm{Hg} \\
D B P \geq 90 \mathrm{~mm} \mathrm{Hg}\end{array}$ & 362 & 66,9 \\
\hline $\begin{array}{l}\text { Known Hypertension } \\
\text { (on antihypertensive treatment) }\end{array}$ & 318 & 58,8 \\
\hline Unknown Hypertension & 44 & 8,1 \\
\hline
\end{tabular}

DMT2:Type 2 Diabetes; IGT: Impaired Glucose Tolerance; IFG: Impaired Fasting Glucose; BMI: Body Mass Index; WHR:Waist -to- Hip Ratio; M: Male; F: Female; SBP: Systolic Blood Pressure; DBP: Diastolic Blood Pressure. 
TABLE 2. Population with laboratory examination for Lipid profile and cardiometabolic risk indicators

\begin{tabular}{|c|c|c|}
\hline & $\mathrm{n}=\mathbf{2 0 6}$ & $\begin{array}{c}\text { Values } N(\%) \\
\text { or mean } \pm \text { SD }\end{array}$ \\
\hline \multicolumn{3}{|l|}{ Sex } \\
\hline Male & 88 & 42,7 \\
\hline Female & 118 & 57,3 \\
\hline Total & 206 & 100 \\
\hline Age & 206 & $62,5 \pm 10,5$ \\
\hline \multicolumn{3}{|l|}{ Lipid profile } \\
\hline $\mathrm{CHOL} \geq 240 \mathrm{mg} / \mathrm{dl}$ & 28 & 13,6 \\
\hline CHOL $200-239$ mg/dl & 67 & 32,5 \\
\hline $\mathrm{CHOL}<200 \mathrm{mg} / \mathrm{dl}$ & 111 & 53,9 \\
\hline $\mathrm{HDL}-\mathrm{CHOL}<40 \mathrm{mg} / \mathrm{dl}$ & 23 & 11,2 \\
\hline HDL-CHOL 40-59 mg/dl & 119 & 57,8 \\
\hline $\mathrm{HDL}-\mathrm{CHOL} \geq 60 \mathrm{mg} / \mathrm{dl}$ & 64 & 31 \\
\hline Male HDL-CHOL < 35 mg/dl & 3 & 3,4 \\
\hline Male HDL-CHOL $\geq 35 \mathrm{mg} / \mathrm{dl}$ & 85 & 96,6 \\
\hline Female $\mathrm{HDL}-\mathrm{CHOL}<45 \mathrm{mg} / \mathrm{dl}$ & 12 & 10,2 \\
\hline Female HDL-CHOL $\geq 45 \mathrm{mg} / \mathrm{dl}$ & 106 & 89,8 \\
\hline LDL-CHOL $\geq 190$ mg/dl & 3 & 1,5 \\
\hline LDL-CHOL 160-189 mg/dl & 9 & 4,4 \\
\hline LDL-CHOL 130-159 mg/dl & 48 & 23,4 \\
\hline LDL-CHOL 100-129 mg/dl & 74 & 36,1 \\
\hline LDL-CHOL $<100$ mg/dl & 71 & 34,6 \\
\hline $\mathrm{TG} \geq 500 \mathrm{mg} / \mathrm{dl}$ & 3 & 1,5 \\
\hline TG 200-499 mg/dl & 37 & 18 \\
\hline TG $150-199$ mg/dl & 34 & 16,5 \\
\hline $\mathrm{TG}<150 \mathrm{mg} / \mathrm{dl}$ & 132 & 64,1 \\
\hline
\end{tabular}

Cardiovascular markers

\begin{tabular}{lcc}
\hline Lp (a) $>30 \mathrm{mg} / \mathrm{dl}$ & 68 & 33 \\
Lp (a) $0-30 \mathrm{mg} / \mathrm{dl}$ & 138 & 67 \\
Apo- B/ Apo - A1 ratio Total & 40 & 19,4 \\
Apo- B/ Apo - A1 ratio Male > 1,0 & 19 & 21,6 of male \\
Apo- B/ Apo - A1 ratio Female $>0,90$ & 21 & 17,8 of female \\
\hline
\end{tabular}

CHOL: Total Cholesterol; HDL-CHOL: high density lipoprotein-cholesterol; LDL-CHOL: low density lipoprotein-cholesterol; TG: Triglycerides; Apo-A: Apolipoptotein A1; Apo-B: Apolipoptotein B; and Lp (a): Apolipoptotein Lp (a).

with BMI 25-30 kg/m2, while normal/underweight with $\mathrm{BMI}<25 \mathrm{~kg} / \mathrm{m} 2$ were $14.1 \%$.

b) Central Obesity: $86.8 \%$ of women and $58.6 \%$ of men had central obesity with waist circumference values $\geq 88$ $\mathrm{cm}$ and $102 \mathrm{~cm}$ respectively. For WHR (Waist / Hip Ratio) values $\geq 1.0: 50.6 \%$ of men and for WHR $\geq 0.90: 72.8 \%$ of women had a central distribution of fat tissue.

c) Hypertension: $66.9 \%$ of the sample had hypertension with $58.8 \%$ on antihypertensive treatment.

d) Lipid profile: In the selected sample of 206 individuals, with $\mathrm{CHOL}$ values $200-239 \mathrm{mg} / \mathrm{dl}$ were $32.5 \%$ of individuals and $13.6 \%$ with CHOL values $\geq 240 \mathrm{mg} / \mathrm{dl}$. $42.7 \%$ of men with HDL - CHOL values $<35$ and $10.2 \%$ of women with $\mathrm{HDL}-\mathrm{CHOL}$ values <45. At LDL-CHOL levels $130-159 \mathrm{mg} / \mathrm{dl}$ were $23.7 \%$ of women and $1.5 \%$ at LDLCHOL levels $\geq 190 \mathrm{mg} / \mathrm{dl}$. A total of $19.5 \%$ of individuals were found to have hypertriglyceridemia (18\% with TG values: $200-499 \mathrm{mg} / \mathrm{dl}$ and $1.5 \%$ with severe hypertriglyceridemia: TG $\geq 500 \mathrm{mg} / \mathrm{dl}$ ) (Table 2).

e) Metabolic Syndrome: The highest prevalence of MetS (92.2\%) was found using the criteria of A. A.C.E 2002, and there was $100 \%$ correlation between the diagnosis of MetS and the diagnosis of unknown DM T2 and 90.3\% with a diagnosis of IGT Table 3-4, and

z) Cardiovascular risk: $52.43 \%$ were found to be at a high risk level, based on the atherosclerotic index Apo-B / Apo -A1: 19.43\% and based on the values of $L p(a): 33$ $\%$ (Table.2).

\section{DISCUSSION}

The present study is the most recent attempt to record the prevalence of DM T2 and the cardiometabolic risk parameters in the Greek population. The results confirm the raising trend in the prevalence of DM T2 as well as of obesity and the related metabolic disturbances that characterize the MetS and, also, are in agreement with the predictions of IDF for the rapid increase in the incidence of DM T2 worldwide ${ }^{1-4}$.

The studies for the prevalence of DMT2 in Greece, belong to two different categories: a) self - reporting, in which an individual answers the question whether he/she is suffering from DM ,or medical record reviewing, and b) blood glucose measurement and the performance of OGTT. It is obvious that the studies of the second category are more sensitive, revealing cases of undiagnosed DM and Prediabetes, and the estimated prevalence is expected to be higher ${ }^{1}$.

The so far studies show the increasing trend in the prevalence of DM in the Greek population. Thus, in the region of Attica, the prevalence increased from $2.4 \%$ in the year 1974 to $9.5 \%$ (studies of self reporting) or to $11.6 \%$ (massuments of blood glucose and OGTT) in the year $2006^{10-11}$. Regarding the rural population, where prevalence was low (1.5\%) during 1988-1993 there was a dramatic increase to $11.7 \%$ during $2003-2005$, so it became similar to urban population ${ }^{12-13}$. This change is similar to 
TABLE 3. Population with MetS according to AACE 2002 criteria

\begin{tabular}{lccc}
\hline Criteria MetS AACE 2002 & & $\mathrm{n}=206$ & Values N (\%) \\
\hline BMI $\geq 25 \mathrm{Kgr} / \mathrm{m}^{2}$ & Male & Female \\
\hline And of these people who meet $\geq 2$ factors from the following: & 78 & 114 & 94,7 \\
Waist circumference & $\geq 102 \mathrm{~cm}$ & 112 & 92,2 \\
SBP & $\geq 130 \mathrm{~mm} \mathrm{Hg}$ & $\geq 130 \mathrm{~mm} \mathrm{Hg}$ \\
DBP & $\geq 85 \mathrm{~mm} \mathrm{Hg}$ & $\geq 85 \mathrm{~mm} \mathrm{Hg}$ \\
& Antihypertensive treatment & Antihypertensive treatment \\
TG & $\geq 150 \mathrm{mg} / \mathrm{dl}$ & $\geq 150 \mathrm{mg} / \mathrm{dl}$ \\
HDL-CHOL & $\leq 40 \mathrm{mg} / \mathrm{dl}$ & $\leq 50 \mathrm{mg} / \mathrm{dl}$ \\
IFG & $\geq 100 \mathrm{mg} / \mathrm{dl}$ & $\geq 100 \mathrm{mg} / \mathrm{dl}$ \\
\hline
\end{tabular}

BMI: Body Mass Index; TG:Triglycerides; SBP: Systolic Blood Pressure; DBP: Diastolic Blood Pressure; HDL-CHOL: high density lipoprotein-cholesterol; IFG: Impaired Fasting Glucose.

TABLE 4. Recognition of DMT2 and IGT cases based on MetS criteria

\begin{tabular}{lcccc}
\hline & $\mathrm{n}=19^{*}$ & $\begin{array}{c}\text { Values N } \\
(\%)\end{array}$ & $\mathrm{n}=31$ & $\begin{array}{c}\text { Values N } \\
(\%)\end{array}$ \\
\hline Criteria & MD T2 & & IGT & \\
MetS WHO 1999 & 17 & 89,5 & 22 & 71 \\
MetS NCEP III 2001 & 13 & 68,4 & 15 & 48,4 \\
MetS NCEP-R 2004 & 14 & 73,7 & 17 & 54,8 \\
MetS AACE 2002 & 19 & 100 & 28 & 90,3 \\
MetS IDF 2006 & 14 & 73,7 & 18 & 58 \\
\hline
\end{tabular}

*plus 2 people with random IFG $\geq 200 \mathrm{mg} / \mathrm{dl}$ measurement with typical symptoms of hyperglycemia.

DM T2: Type 2 Diabetes; IGT: Impaired Glucose Tolerance; mets: Metabolic Syndrome; WHO: World Health Organization; NCEP III: National Cholesterol Education Program 2001; NCEP-R: American Heart Association National Heart, Lung, and Blood Institute 2004; AACE: American Association of Clinical Endocrinologists 2002; IDF: International Diabetes Federation 2006.

the rising trend worldwide, and the cause of this increase is the change in the lifestyle, with a consequent decrease in physical activity, junk food and obesity ${ }^{3}$.

The present study followed combined methodology: self - reporting of DM in the study population and measurement of blood glucose and OGTT in the selected sample of people after the use of the FINDRISK questionnaire ${ }^{6}$.The FINDRISK has been evaluated and used as a tool for the detection of people with an increased risk of developing DM and MetS ${ }^{14}$.

The data of the present study revealed that during the years 2015-2016, the prevalence of DMT2 in the rural population in the region of Evros has increased considerably at the level of $29.6 \%$. A similar increase has been noted in all the cardio metabolic risk parameters, as in obesity and especially in central obesity, in hypertension and in dyslipidemia.

In compassion with the data provided by papazoglou et $\mathrm{al}^{5}$ in the year 1993, when the prevalence of DM T2 in the prefecture of Evros was $1.6 \%$ (study of reviewing data from medical notes and records of local pharmacies) a rapid increase in the incidence of DM has been observed within two decades, Although the two studies differ regarding the methodology, it is obvious that the increase should be attributed to the changes in the socio economic conditions over the last decades in Greece with the consequent dramatic changes in the lifestyle of the inhabitants of rural Greek villages. Another parameter that should be considered is the changes in the population synthesis in the Greek rural areas with the greater proportion belonging to the aging population.

A limitation of the present study, that should be considered, is the relatively small number of the initial population study, and consequently the small number of the selective sample of people in response to FINDRISK questionnaire, who underwent the laboratory investigation for the detection of undiagnosed DM and Prediabetes, as well as for the measurement of the lipid profile and detection of the prevalence of the MetS.

Obviously the selective sample is, by definition, sample with increased risk for developing metabolic disorders. This also explains the rather high prevalence of the MetS in the present study.

In conclusion, the present study represents the most recent attempt for the detection of the prevalence of DM $\mathrm{T} 2$ in the rural population of Evros, and shows the rapid increase of the disease and the related cardiometabolic risk parameters to epidemic laves. As a consequence, measures should be taken to prevent this epidemic that should be aiming in changing the lifestyle of the Greek population. 


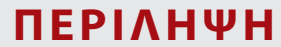

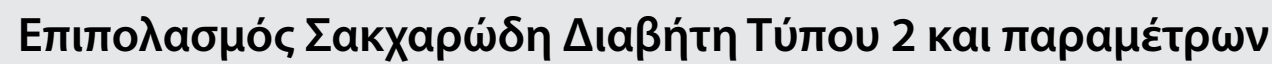

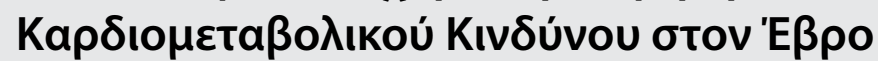

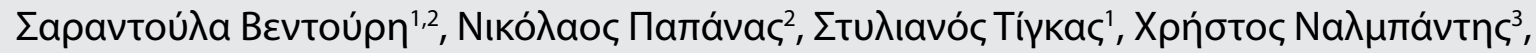

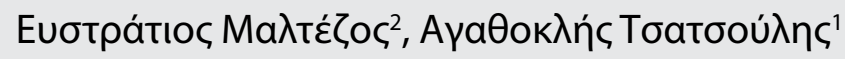

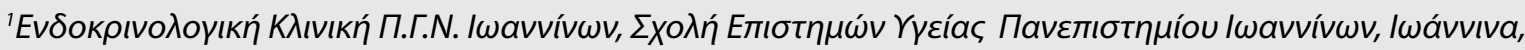

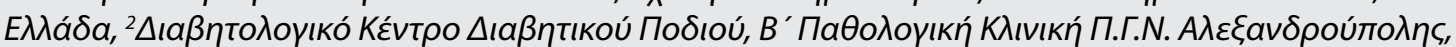

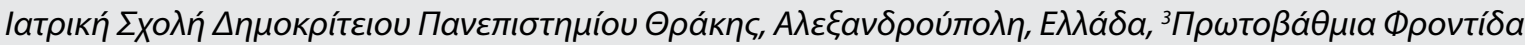

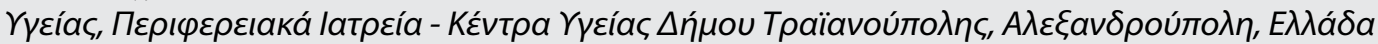

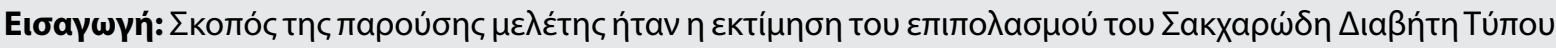

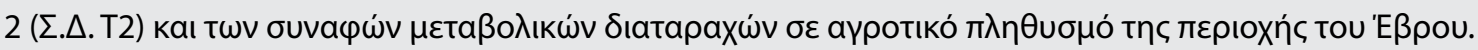

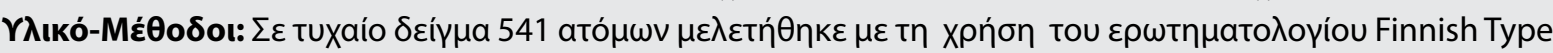

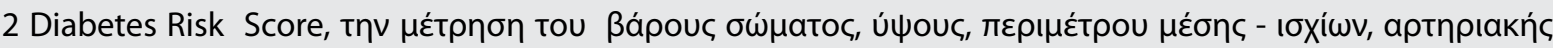

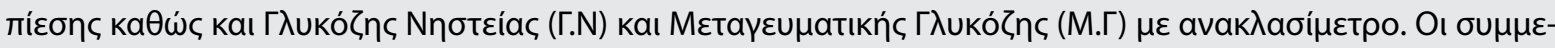

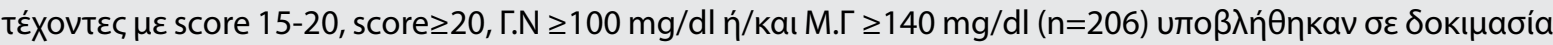

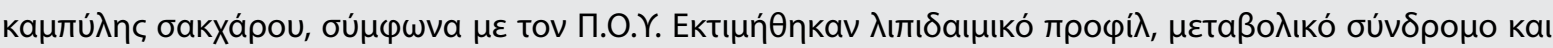

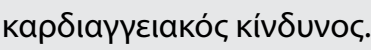

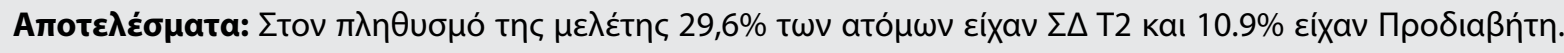

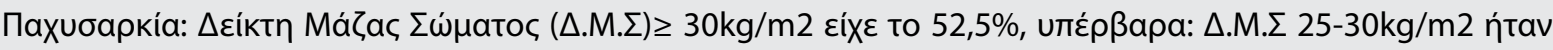

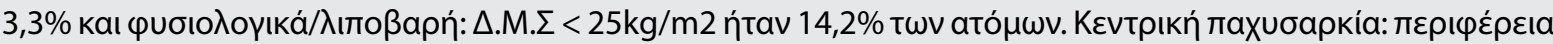

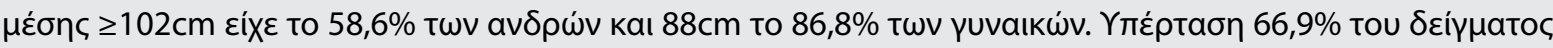

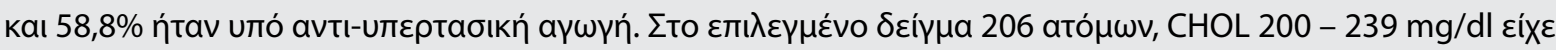

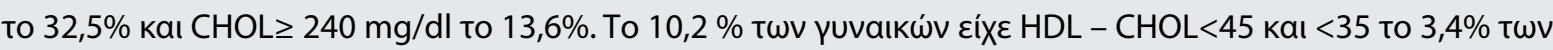

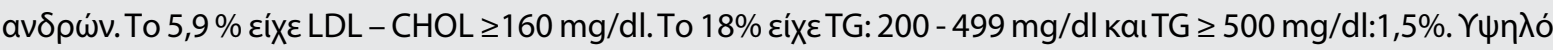

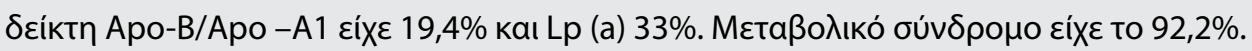

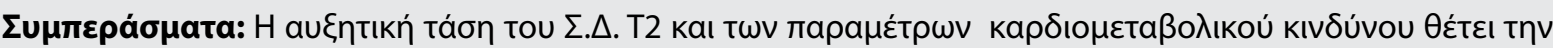

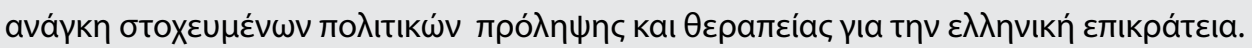

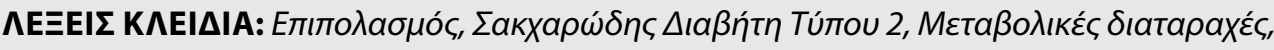

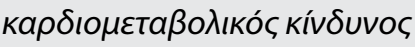

\section{REFERENCES}

1. Loupa C, Kalantzi S, Maris A. Trends in epidemiology of Diabetes Mellitus in Greece. Review of epidemiological studies. Clin Case Rep Rev. 2017;3(10):1-4. Doi: 10.15761/ CCRR.1000371.

2. Touloumi G, Karakosta A, Kalpourtzi N, Gavana M, Vantarakis A, Kantzanou M, et al. High prevalence of Cardiovascular risk factors in adults living in Greece: The EMENO National Health Examination Survey. BMC Public Health [Internet]. 2020 Nov [2021 Aug 27];1665. Available from: https://bmcpublichealth.biomedcentral. com/articles/10.1186/s1 2889-020-09757-4.

3. Anagnostis P. Metabolic syndrome in the Mediterranean region: Current status. Indian J Endocrinol Metab. 2012 Jan-Feb;16(1):72-80.

4. Intermnationl Diabetes Federation. Global Burden: Preva- lence and Projections 2011 and 2030. 2011 [2015 Apr 27]. Available from: http://www. diabetes atlas. org/ content/ diabetes-and-impaired glucose tolerance.

5. Papazoglou N, Manes C, Soulis G, Kirtzis I, Christakidis D, Nikolaidis I, et al. Epidemoiology of Diabetes in Greece. II Evros County, (9 article in Greek). Hellenic Dialectological Chronicle.1993;6:134-140.

6. Lindstrom J, Tuomilehto J. The diabetes risk score: A practice tool to predict type 2 diabetes risk. Diabetes Care. 2003 Mar;26(3):725-31.

7. Report of World Health Organization and International Diabetes Federation meeting. Screening for Type 2 Diabetes. 2003. [2015 Apr 27]. Available from: https://apps. who.int/iris/handle/10665/68614.

8. Marcovina S, Packard CJ. Measurement and meaning of apolipoprotein Al and apolipoprotein B plasma levels. J 
Intern Med. 2006 May;259(5):437-46.

9. Walldius G, Jungner I. The apoB/Apo A-I radio: A strong, new risk factor for cardiovascular disease and a target for lipid-lowering therapy - a review of the evidence. J Intern Med. 2006 May;259(5):493-519.

10. Katsilampros N, Aliferis K, Darviris C, Tsapogas P, Alexiou $Z$, Tritos N, et al. Evidence for an increase in the prevalence of known Diabetes in a sample of an urban population in Greece. Diabetic Medicine [Internet].1993 Jan-Feb [2014 Apr 27];10:87-90. Available from: https:// doi.org/10.1111/j.1464-5491.1993.tb02002.x

11. Panagiotakos DB, Pitsavos C, Chrysohoou C, Skoumas I, Stefanadis C. Prevalence and five-year incidence (20012006) of cardiovascular disease risk factors in a Greek Sample: the ATTICA study. Hellenic J Cardiol. Sep-Oct
2009;50(5):388-95.

12. Gikas A, Sotiropoulos A, Panagiotakos DB, Pastromas V, Paraskeyopoulou E, Skliros E, et al. Rising prevalence of diabetes among Greek adults: findings from two consecutive surveys in the same target population. Diabetes Res Clin Pract. 2008 Feb;79(2):325-9.

13. Melidomis A, Tournis S, Kompoti MG, Lentzas I, Roussou VR, Iraklianou SL, et al. Increased prevalence of Diabetes mellitus in a rural Greek population. Rural Remote Health. 2006 Jan-Mar;6(1):534.

14. Makrilakis S, Liatis S, Grammatikou S, Perrea D, Stathi C, Tsiligros $\mathrm{P}$, et al. Validation of the Finish Diabetes Risk Score (FINDRISK) questionnaire for screening for undiagnosed type 2 Diabetes, dysglycaemia and the Metabolic Syndrome in Greece. Diabetes Metab. 2011 Apr;37(2):144-51. 